\title{
Technisch rapport WO-Monitor 1998
}

Citation for published version (APA):

van der Velden, R. K. W., Allen, J. P., van der Kolk, P., \& Huijgen, T. G. (2000). Technisch rapport WO-

Monitor 1998. Researchcentrum voor Onderwijs en Arbeidsmarkt, Faculteit der Economische

Wetenschappen. ROA Working Papers No. 8 https://doi.org/10.26481/umarow.2000008

Document status and date:

Published: 01/01/2000

DOI:

10.26481/umarow.2000008

Document Version:

Publisher's PDF, also known as Version of record

\section{Please check the document version of this publication:}

- A submitted manuscript is the version of the article upon submission and before peer-review. There can be important differences between the submitted version and the official published version of record.

People interested in the research are advised to contact the author for the final version of the publication, or visit the DOI to the publisher's website.

- The final author version and the galley proof are versions of the publication after peer review.

- The final published version features the final layout of the paper including the volume, issue and page numbers.

Link to publication

\footnotetext{
General rights rights.

- You may freely distribute the URL identifying the publication in the public portal. please follow below link for the End User Agreement:

www.umlib.nl/taverne-license

Take down policy

If you believe that this document breaches copyright please contact us at:

repository@maastrichtuniversity.nl

providing details and we will investigate your claim.
}

Copyright and moral rights for the publications made accessible in the public portal are retained by the authors and/or other copyright owners and it is a condition of accessing publications that users recognise and abide by the legal requirements associated with these

- Users may download and print one copy of any publication from the public portal for the purpose of private study or research.

- You may not further distribute the material or use it for any profit-making activity or commercial gain

If the publication is distributed under the terms of Article $25 \mathrm{fa}$ of the Dutch Copyright Act, indicated by the "Taverne" license above, 


\section{Technisch rapport WO-Monitor 1998}

\section{ROA-W-2000/8}

J. Allen, T. Huijgen, P. van der Kolk en R. van der Velden

Researchcentrum voor Onderwijs en Arbeidsmarkt

Faculteit der Economische Wetenschappen en Bedrijfskunde Universiteit Maastricht

Maastricht, maart 2000 
ISBN 90-5321-299-X

Sec00003/RvdV 
Inhoud

Bladzijde

1 Inleiding 1

$\underline{2}$ Organisatie van de WO-Monitor $\quad 1$

$\underline{3} \quad \underline{V}$ ragenlijst 3

4 Dataverzameling 4

$\underline{5}$ Dataverwerking 7

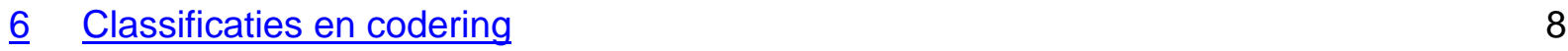

$\underline{7}$ Databeheer 10

$\underline{8}$ Evaluatie 10

$\begin{array}{lll}\text { Bijlage 1: } \quad \text { Vragenlijst WO-Monitor } 1998 & 15\end{array}$

Bijlage 2: $\quad$ Vragenlijst WO-Monitor 1999 



\section{Inleiding}

In 1998 is onder auspiciën van de VSNU de WO-Monitor van start gegaan. Aanleiding hiervoor was de behoefte om over landelijke gegevens te beschikken met betrekking tot de arbeidsmarktintrede van afgestudeerden. Weliswaar werd op diverse plaatsen reeds onderzoek verricht naar de overgang van het WO naar de arbeidsmarkt, maar door de uiteenlopende designs en vraagstellingen leverde dit geen onderling vergelijkbare gegevens op. Het Algemeen Bestuur van de VSNU heeft daarom besloten tot invoering van een landelijke WO-Monitor, waarin alle universiteiten participeren.

Bij de organisatorische opzet van de WO-Monitor zijn twee uitgangspunten gehanteerd. Enerzijds zou de WO-Monitor zoveel mogelijk moeten aansluiten bij de reeds bestaande lokale initiatieven, anderzijds is ook het belang benadrukt van onderlinge afstemming en afstemming met andere databronnen. In het bijzonder is daarbij gewezen op de Enquête Beroepsbevolking (EBB) van het Centraal Bureau voor de Statistiek (CBS) en het schoolverlatersonderzoek dat het ROA voor de overige onderwijstypen uitvoert.

Gekozen is voor een organisatiemodel waarbij de universiteiten zelf verantwoordelijk zijn voor de dataverzameling en -verwerking. Voor de opzet hiervan worden echter landelijke richtlijnen opgesteld. Het ROA heeft in opdracht van de VSNU de landelijke coördinatie verzorgd.

Het voorliggende rapport vormt het technisch verslag van de werkzaamheden die verricht zijn in het kader van de WO-Monitor 1998. Daarnaast verschijnt in het najaar van 1999 de 'Kengetallenpublicatie WO-Monitor 1999', waarin een inhoudelijke analyse wordt verricht naar de transitie van opleiding naar werk voor afgestudeerden van het WO. Voorst is een bestandsdocumentatie opgeleverd met een specificatie van het variabelenbestand en de constructie van nieuwe variabelen. Ten slotte is een 'Beheers- en gebruiksreglement WOMonitor' opgesteld (verkrijgbaar bij de VSNU), waarin het gebruik van de onderzoeksgegevens is gereglementeerd.

De opzet van het voorliggend rapport is als volgt. Na een korte schets van het organisatiemodel (hoofdstuk 2), zal achtereenvolgens worden ingegaan op de vragenlijst (hoofdstuk 3 ), de dataverzameling (hoofdstuk 4), de dataverwerking (hoofdstuk 5), classificatie en codering (hoofdstuk 6) en databeheer (hoofdstuk 7). Het rapport wordt afgesloten met een korte evaluatie (hoofdstuk 8).

\section{Organisatie van de WO-Monitor}

Zoals aangeven is voor de uitvoering van de WO-Monitor gekozen voor een decentraal model, waarbij de universiteiten zelf verantwoordelijk zijn voor de uitvoering. Deze uitvoering dient volgens een landelijk format plaats te vinden. De universiteiten kunnen eventueel buiten het landelijk vastgestelde format vragen toevoegen die relevant zijn voor de eigen instelling. 
Bij de uitvoering van de WO-Monitor kunnen de volgende partijen onderscheiden worden:

1. Afzonderlijke universiteiten die fungeren als opdrachtgever voor de lokale uitvoering van de WO-Monitor.

2. Onderzoeksinstituten verantwoordelijk voor de lokale uitvoering. Een deel van de universiteiten heeft overigens de lokale uitvoering uitbesteed. Lokale uitvoerders zijn: GION (RUG), Onderwijskundig Centrum (UT), FSW/STOGO (UU), IOWO (KUN), SCO (in samenwerking met ROA: UvA), STOAS (eveneens in samenwerking met ROA: LUW) en ROA (UM, TUE, KUB, EUR, TUD, LEI, VU). De lokale uitvoerders zijn verantwoordelijk voor de lokale steekproeftrekking, dataverzameling, dataverwerking, codering en datacleaning. Voorts voeren de lokale uitvoerders overleg met de 'eigen' universiteit omtrent het eventueel toevoegen van vragen en over de rapportage van de instellingsspecifieke gegevens.

3. De landelijke coördinatie die door de VSNU in handen is gelegd van het ROA. De landelijke coördinator is verantwoordelijk voor het opstellen van richtlijnen omtrent onderzoekspopulatie, vragenlijst, dataverzameling, dataverwerking, codering en datacleaning. Daarnaast is de coördinator verantwoordelijk voor de koppeling van de lokale databestanden, het maken van nieuwe centrale variabelen, het verzorgen van voor derden toegankelijke bestandsdocumentatie en het technisch bestandsbeheer.

4. De VSNU onder wiens auspiciën de landelijke WO-Monitor wordt uitgevoerd. De VSNU is opdrachtgever voor de landelijke coördinator en houder van het landelijke onderzoeksbestand, zoals vastgelegd in het 'Beheers- en gebruiksreglement WO-Monitor'. Daarnaast verstrekt de VSNU opdracht aan één of meerdere instituten om een 'Kengetallenrapportage WO-Monitor' te maken die door de VSNU wordt uitgebracht.

5. SCO en ROA zijn verantwoordelijk voor het opstellen van de 'Kengetallenrapportage WO-Monitor'.

6. Vertegenwoordigers van andere organisaties (op dit moment WASA en CBS) die een adviserende taak hebben ten aanzien van de opzet van de WO-Monitor.

Waar in de rest van het verslag gesproken wordt over de 'WO-Monitor' wordt bedoeld de activiteiten die verricht worden in het kader van het landelijk deel van de WO-Monitor en worden de 'lokale' toevoegingen buiten beschouwing gelaten.

Bij de uitvoering van de WO-Monitor wordt overleg gevoerd in twee gremia. De begeleidingsgroep, bestaande uit VSNU, lokale uitvoerders, specifieke deskundigen en instellingsvertegenwoordigers, is belast met het toezicht houden op de gemaakte afspraken en de uitvoering van de WO-Monitor. Deze begeleidingsgroep staat onder voorzitterschap van Prof.dr. J. Peschar. Het ROA voert het secretariaat. De begeleidingsgroep is in de periode januari 1998 tot juni 19998 maal bijeen geweest.

Daarnaast voert het ROA overleg met de lokale uitvoerders in de zogeheten technische werkgroep. Hier worden meer specifieke details omtrent de uitvoering besproken. Ook deze werkgroep is verschillende malen bijeen geweest, en heeft daarnaast via e-mail contact onderhouden. 


\section{Vragenlijst}

In bijlage 1 is de vragenlijst van de WO-Monitor 1998 te vinden. De vragen die aan de respondenten zijn voorgelegd kunnen in vijf blokken worden verdeeld. Naast enkele algemene vragen over het geboortejaar en woonplaats e.d., waren er vragen over de gevolgde WOopleiding, de werkgelegenheidssituatie, de arbeidsmarktintrede en werkervaring en vragen over de functie die de respondenten hadden ten tijde van enquêtering. De lokale uitvoerders moeten er voor zorgen dat de vragen van deze zogenaamde VSNU-vragenlijst aan de afgestudeerden worden voorgelegd. Lokale uitvoerders hadden uiteraard de mogelijkheid om daarnaast nog andere vragen te stellen.

Met betrekking tot de het stellen van deze standaardvragen hebben zich drie problemen voorgedaan. Ten eerste heeft niet iedereen de vragen letterlijk gesteld zoals ze in de VSNUlijst waren afgesproken (bijvoorbeeld vraag 20). Zo is onder andere gebleken dat met name het toevoegen of weglaten van een toelichting van invloed kan zijn op de antwoorden die men krijgt. Ten tweede is soms een vraag helemaal niet gesteld maar is de variabele behorende bij de desbetreffende vraag achteraf aangemaakt aan de hand van antwoorden op andere vragen uit de vragenlijst (bijvoorbeeld vraag 18 en vragen over de intredewerkloosheid). Ten derde bleek dat de vragenlijst zelf voor verbetering vatbaar is. Vooral de verwijzingsstructuur in de lijst was niet altijd even eenvoudig en daardoor moeilijk in te passen in de werkelijke vragenlijsten. Dit omdat de feitelijke vragenlijsten van alle uitvoerders meer vragen bevatten dan alleen de standaard VSNU-vragen hetgeen leidt tot langere en complexere enquêtes. Het belang van deze drie aspecten werd vooral duidelijk bij het koppelen van de bestanden van alle lokale uitvoerders en bij het aanmaken van de kernindicatoren zoals die in het landelijke bestand terug te vinden zijn.

Door genoemde, kleine afwijkingen in de vraagstelling bij de enquêtering kan een enkele universiteit beter of slechter scoren op een kernindicator. Voor zover mogelijk is hiervoor in de data-cleaning gecorrigeerd. Omdat kernindicatoren belangrijke informatie bevatten (zoals bijvoorbeeld werkloze/werkzame beroepsbevolking en maatschappelijke positie) en verschillen tussen universiteiten van enkele procentpunten al vragen kunnen oproepen dienen deze afwijkingen vermeden te worden. Om deze problemen in de toekomst te voorkomen is tussen de lokale uitvoerders afgesproken dat de vragen, zoals deze zijn vastgesteld voor de WO-Monitor 1999, letterlijk dienen te worden overgenomen. Dit geldt zowel voor de vragen zelf als voor eventuele toelichtingen. Daarnaast dient de verwijzingsstructuur aangehouden te worden.

Ook in de vragenlijst zelf zijn enige wijzigingen aangebracht (de vragenlijst voor de WO-Monitor 1999 staat in bijlage 2). Zo is er in het blok over de gevolgde opleiding een duidelijkere verwijzingsstructuur aangebracht (was erg ondoorzichtig) en zijn de vragen in dit blok over het voortraject ingekort. In het blok dat handelt over de werkgelegenheidssituatie is er naast de vraag welke omschrijvingen (zie vraag 18 vragenlijst 1999) op de respondent van toepassing zijn eveneens gevraagd welke van deze omschrijvingen het meest van toepassing is. Dit omdat er bij de eerste vraag meerdere antwoorden mogelijk zijn en het hierdoor lastig is gebleken om de (subjectieve) maatschappelijke positie van respondenten te bepalen. Ten 
opzichte van 1998 zijn verder de vragen omtrent (intrede-) werkloosheid aangescherpt. In het deel met vragen over de huidige functie wordt nu expliciet gevraagd of iemand betaald werk heeft (zogenaamde verwijzingsvraag). Dit heeft een duidelijkere verwijzingsstructuur tot gevolg en voorkomt dat informatie afgeleid moet worden uit antwoorden op andere vragen. Het maken van zogenaamde afgeleide variabelen leidt met name tot problemen wanneer respondenten een vragenlijst (of een deel ervan) niet consistent, of deels niet invullen. In ditzelfde onderdeel van de lijst zijn eveneens vragen toegevoegd met betrekking tot het vereiste opleidingsniveau en de vereiste opleidingsrichting. Een andere belangrijke wijziging ten slotte is doorgevoerd bij vragen over de arbeidsduur (zie o.a. vraag 48 van de nieuwe lijst). Er wordt nu niet alleen naar het aantal uren gevraagd maar ook hoeveel procent van een voltijdbetrekking dit aantal uren is.

\section{Dataverzameling}

Populatie

In de WO-Monitor van 1998 zijn alle afgestudeerden benaderd die tussen 1 oktober 1996 en 30 september 1997 zijn afgestudeerd. Alleen bij de Vrije Universiteit van Amsterdam zijn afgestudeerden uit de periode van 1 januari 1997 tot en met 31 december 1997 benaderd. Het onderzoek had betrekking op afgestudeerden die een initiële universitaire opleiding hebben afgesloten als doctorandus, meester, ingenieur, basisarts, tandarts of apotheker. Tevens worden tot de populatie gerekend zij die de opleiding hebben beëindigd na het behalen van het getuigschrift op grond van 168 studiepunten in het kader van een opleiding tot arts, tandarts, dierenarts of apotheker. Voor diegenen die in deze opleidingen na hun doctoraalopleiding doorstromen naar de beroepsopleiding tot basisarts, tandarts, dierenarts of apotheker betekent dit dat zij pas na het behalen van het betreffende diploma worden benaderd. De adressenbestanden zijn aangeleverd door de universiteiten zelf. Afgestudeerden die in genoemde periode meerdere studies aan dezelfde universiteit hebben afgerond zijn toch maar één keer benaderd. De universiteit heeft in dergelijke gevallen bepaald voor welke opleiding de afgestudeerde benaderd moest worden. Als aanvulling op de WO-Monitor is er eveneens een meting gehouden onder afgestudeerden van de universitaire lerarenopleidingen. De gegevens die met deze meting verzameld zijn behoren echter niet tot het reguliere onderzoeksbestand.

\section{Datacollectie en respons}

Begin oktober 1998 zijn de vragenlijsten verstuurd. De sluitingstermijn voor de respons was 15 januari 1999. Alle instellingen hebben in deze periode tenminste één rappel verstuurd aan afgestudeerden die nog niet gereageerd hadden, de meeste instellingen hebben zelfs een tweede rappel verstuurd. Alle universiteiten hebben de enquête schriftelijk afgenomen, behalve de Universiteit Utrecht die telefonisch heeft geënquêteerd. Er is vanuit gegaan dat dit, behalve voor de respons, verder niet van invloed is geweest op de beantwoording van de vragenlijst. In totaal zijn er 24.836 afgestudeerden benaderd. Ongeveer 11.000 respondenten hiervan hebben schriftelijk gereageerd, ongeveer 2250 respondenten hebben aan de 
telefonische enquêtering meegedaan. Daarnaast zijn ongeveer 1500 verstuurde lijsten geretourneerd omdat ze verkeerd geadresseerd waren (verouderde adressen) en hebben zo'n 270 benaderden expliciet te kennen gegeven dat ze weigerden mee te doen aan het onderzoek.

De respons lag in totaal rond de $50 \%$ hetgeen redelijk is wanneer gekeken wordt naar vergelijkbare onderzoeken. In tabel 1 staan de responscijfers per universiteit weergegeven.

Tabel 1

Responspercentages per universiteit

\begin{tabular}{lccc}
\hline Universiteit & respons & universiteit & respons \\
\hline UvA & & VU & $52,3 \%$ \\
TUD & $41,6 \%$ & TUE & $55,9 \%$ \\
RUG & $53,5 \%$ & LEI & $47,4 \%$ \\
UM & $52,4 \%$ & EUR & $48,4 \%$ \\
KUB & $55,0 \%$ & UU & $69,8 \%$ \\
LUW & $56,8 \%$ & KUN & $43,9 \%$ \\
UT & $59,6 \%$ & & \\
\hline
\end{tabular}

De hoogste respons had de Universiteit Utrecht (bijna 70\%) en de Universiteit van Twente (67\%). De lagere responscijfers zijn te vinden bij de Universiteit van Amsterdam en de Katholieke Universiteit Nijmegen. In het algemeen is het zo dat telefonische enquêtes een hogere respons hebben dan schriftelijke. Daarnaast is in de regel de respons in het westen van het land altijd slechter dan de respons in de rest van Nederland. In tabel 2 staan de responspercentages per HOOP-sector.

Tabel 2

Responspercentages per HOOP-sector

Sector

respons

Economie

Gedrag en Maatschappij

Gezondheidszorg

Landbouw

Natuur

Recht

Taal en Cultuur

Techniek
$47,6 \%$

$57,3 \%$

$58,7 \%$

$59,6 \%$

$56,0 \%$

$46,6 \%$

$50,3 \%$

$56,4 \%$

De responspercentages in de tabellen 1 en 2 kunnen niet allemaal uniform berekend worden. Dit werd veroorzaakt door niet volledige dan wel handmatig bijgehouden responsadministraties. Met name met betrekking tot de non-respondenten is de responsadministratie 
voor verbetering vatbaar. Het is daarom van groot belang hier extra aandacht aan te besteden tijdens de WO-Monitor van 1999.

Het ROA doet jaarlijks een non-respons onderzoek. Dit jaar is er ook gekeken naar de afgestudeerden uit het WO. Doel hiervan is te achterhalen of er sprake is van selectieve (non-) respons. Het mag niet zo zijn dat de groep respondenten en de groep non-respondenten op kenmerken teveel van elkaar verschillen. Een deel van de non-responsgroep is telefonisch benaderd met een klein aantal vragen. Deze groep bevatte 277 non-respondenten van het WO, uiteraard met uitzondering van die universiteiten waarvoor het ROA geen lokale uitvoerder was. Door middel van een Fisher-toets is gekeken of de responsgroep en de nonresponsgroep van elkaar verschillen op de kenmerken bestemming (tabel 3) en betaald werk (tabel 4). Het kenmerk bestemming geeft aan wat respondenten hun belangrijkste bezigheid vinden. lemand die bijvoorbeeld bij dit kenmerk in de categorie 'studie' valt kan dus best ook betaald werk hebben. Uit tabel 3 komt naar voren dat er tussen de groep respondenten en de groep non-respondenten weinig significante verschillen bestaan wanneer gekeken wordt naar bestemming. In de responsgroep hebben mensen iets meer betaald werk als hun belangrijkste bezigheid dan in de non-respons groep. Daarnaast zijn er onder de non-respondenten meer mensen die in de 'anders-categorie' vallen.

Tabel 3

Fisher-toets op selectiviteit naar bestemming tussen respondenten en non-respondenten per onderwijssoort

\begin{tabular}{|c|c|c|c|c|c|}
\hline \multirow{2}{*}{ Bestemming } & \multicolumn{2}{|c|}{ non-respons } & \multicolumn{2}{|c|}{ respons } & \multirow{2}{*}{ z-score } \\
\hline & aantal & $\%$ & aantal & $\%$ & \\
\hline Betaald werk & 270 & 92 & 12.050 & 94 & $-1,37$ \\
\hline Studie & 5 & 2 & 278 & 2 & $-0,33$ \\
\hline Werkloos & 5 & 2 & 344 & 3 & $-1,29$ \\
\hline Anders & 15 & 5 & 162 & 1 & $4,78^{\star \star}$ \\
\hline
\end{tabular}

* significant op 5\%-niveau ** significant op 1\%-niveau

Tabel 4

Fisher-toets op selectiviteit in het aandeel betaald werkende respondenten en het aandeel betaald werkende non-respondenten per onderwijssoort

\begin{tabular}{|c|c|c|c|c|c|}
\hline \multirow[t]{2}{*}{ Betaald werk } & \multicolumn{2}{|c|}{ non-respons } & \multicolumn{2}{|c|}{ respons } & \multirow[t]{2}{*}{ z-score } \\
\hline & aantal & $\%$ & aantal & $\%$ & \\
\hline $\mathrm{Ja}$ & 294 & 95 & 12.162 & 93 & 0,97 \\
\hline Nee & 16 & 5 & 850 & 7 & \\
\hline
\end{tabular}

Als gekeken wordt of er sprake is van selectiviteit in het antwoord op de vraag: 'Heb je op dit moment (ook) betaald werk?', blijkt dat beide groepen niet van elkaar verschillen (zie tabel 4). 


\section{Dataverwerking}

De verwerking van de vragenlijsten die uitgevoerd zijn door of in samenwerking met het ROA berustte bij het marktonderzoekbureau DESAN te Amsterdam. Het data-entry programma is gemaakt door DESAN met het zelf ontwikkelde programma IT. In het programma kan aan elke vraag minimum en maximum waarden worden gegeven, kan al gecontroleerd en gecorrigeerd worden en wordt de verwijzingsstructuur ingebouwd. De waarden en controles worden bepaald door het ROA. Drie van de vier lokale uitvoerders hebben de vragenlijst gescand door middel van OCR (Optical Character Recognition). De andere lokale uitvoerder heeft telefonisch geënquêteerd. Data-entry heeft plaatsgevonden in november 1998 tot en met januari 1999.

\section{Protocol data-cleaning}

Doordat de verwerking van de vragenlijsten op verschillende manieren gebeurde en doordat niet iedereen dezelfde data-entry software heeft, is het protocol niet altijd op dezelfde wijze gehanteerd. Het protocol geeft een overzicht van de volgende zaken:

- de variabelennaam en de grootte;

- de variabelen- en valuelabels;

- controles en correcties met beslisregels;

- verwijzingsstructuur.

Leidraad voor het maken van het protocol is het data-entry programma van DESAN geweest. Er is getracht op overzichtelijke wijze weer te geven wat per vraag gedaan moest worden. Door het ROA zijn controles uitgevoerd op de verschillende onderdelen en zijn waar mogelijk de data verder gecleand.

Voor de WO-Monitor 1999 wordt er voor gekozen om, ondanks de verschillende manieren van enquêteren, het protocol summier te houden teneinde van iedereen ruwe data te ontvangen, die dan centraal door het ROA wordt gecontroleerd en gecorrigeerd. De enige vereisten aan de ruwe data zijn eenduidige variabelenbenoeming, formaat en labels van de variabelen. In feite kiezen we er nu voor om de vragenlijsten zo in te voeren zoals deze zijn ingevuld. De controles en correcties die het ROA in een later stadium zal doorvoeren, zullen gebaseerd zijn op een voorstel dat door de de technische werkgroep geaccordeerd wordt.

$\mathrm{Bij}$ het samenvoegen van de databestanden is er vooraf op drie dingen gecontroleerd. Ten eerste is er gecontroleerd op de juiste vraagstelling. Alle variabelen van identieke vragen zijn samengevoegd. Ten tweede zijn variabelen gehercodeerd indien er afwijkende antwoordmogelijkheden voorgegeven zijn. Wat hier ook onder valt is welke antwoordmogelijkheden als valide worden aangemerkt en welke als missing. Sommige universiteiten hebben aparte codes aangegeven voor missende waarden. Voor het bestand zijn deze omgezet naar sysmis (zonder numerieke code). Ten derde is gecontroleerd op variabelen, die als standaard gelden, maar die niet voor elke universiteit bestaan. Deze worden dan met de voorhanden zijnde informatie aangemaakt. 
De bestanden zijn gecorrigeerd en gekoppeld met behulp van het statistisch programma SPSS versie 8.01 onder Windows '95. Tevens worden de bestanden bewaard en opgeleverd in SPSS formaat als zijnde een *.SAV (systemfile) of een *.POR (portable file). ledere universiteit heeft een SPSS bestand ontvangen, waarbij het niet mogelijk is andere universiteiten behalve de eigen universiteit te onderscheiden.

\section{Nieuwe variabelen}

In het totale samengevoegde bestand van de 13 universiteiten is een aantal variabelen nieuw aangemaakt. Nieuw in de betekenis van toegevoegde of afgeleide variabelen. Er is nog een onderscheid tussen afgeleide VSNU variabelen en ROA variabelen. VSNU variabelen zijn expliciet aangemaakt voor VSNU en zijn duidelijk te herkennen aan de naam (VSNU1, VSNU2 enz.). ROA variabelen zijn onderdeel van het schoolverlatersonderzoek dat ROA ook voor andere sectoren uitvoert.

De toegevoegde of afgeleide variabelen zijn voornamelijk samengestelde variabelen o.b.v. bestaande variabelen in het bestand of hercoderingen van variabelen in klassen. Al deze bewerkingen worden ook in SPSS uitgevoerd. Voor deze variabelen en de syntax wordt verwezen naar het rapport WO-Monitor 1998, Documentatie landelijk onderzoeksbestand bladzijde 8 e.v. De gebruikte syntax blijft bij het ROA bewaard.

\section{Weging}

Basis voor de weging zijn populatiecijfers van het Ministerie van OC\&W. Deze WO-data bevat het aantal afgestudeerden per brincode onderverdeeld naar geslacht. Voor de WO-Monitor is gewogen naar opleiding, voltijd/deeltijd, instelling en geslacht. Voor de WO-Monitor is de $\mathrm{CROHO}$ codering gebruikt voor de weging. Deze is via een sleutel te herleiden tot de ROA opleidingsclassificatie op 6-digit niveau. Daar de WO-populatiedata geen onderscheid geeft in voltijd of deeltijd, wordt deze variabele op code 1 (voltijd) gezet. In SPSS worden de populatiematrix en respondentenmatrix aangemaakt. Vervolgens worden deze matrices ingelezen in PASCAL en wordt per opleiding, voltijd, instelling en geslacht het populatieaantal gedeeld door het steekproefaantal. Op de hieruit verkregen wegingsfactor worden enkele controles en correcties uitgevoerd op basis van een aantal beslisregels.

Uiteindelijk resulteert dit in een wegingsfactor per respondent, waarbij de wegingsfactor tevens zorgt voor een projectie naar populatieaantallen. Er is voor gekozen om de wegingsfactor vooralsnog niet te gebruiken. Het is zinvol om in de technische begeleidingscommissie hier verdere afspraken over te maken.

\section{Classificaties en codering}

In de vragenlijst van de WO-Monitor zijn enkele open vragen opgenomen. Het betreft met name vragen die betrekking hebben op beroep, vervolgopleiding en het bedrijf c.q. de branche waar mensen werkzaam zijn. Om met de gegevens uit deze open vragen te kunnen 
werken dienen ze omgezet te worden naar codes. Voor deze coderingen zijn classificaties nodig. Het coderen van deze open vragen is vrij bewerkelijk en er is enige expertise voor nodig. Om het een en ander toe te lichten is er, voor lokale uitvoerders en andere geïnteresseerden, eind 1998 een instructiemiddag geweest (deze werd verzorgd door DESAN Marktonderzoek BV). Tevens bestond er de mogelijkheid om het coderen centraal te laten uitvoeren, 11 van de 13 universiteiten hebben hier gebruik van gemaakt.

De gevolgde opleidingen zijn gecodeerd op basis van het Centraal Register Opleidingen Hoger Onderwijs (CROHO). Dit is een (4-digit) code welke uniek is voor iedere opleiding. Het voordeel van deze indeling is dat het binnen het hoger onderwijs een vaak, en dus bekende, gehanteerde indeling is. Een nadeel van deze indeling is dat er weinig systeem in zit. In feite is het niet meer dan een unieke code per opleiding die bijvoorbeeld niets zegt over de aard van de opleiding (voltijd/deeltijd, duur e.d.). Aangezien er bij sommige opleidingen diverse richtingen te onderscheiden zijn is een codering op basis van $\mathrm{CROHO}$ niet altijd even geschikt. De opleiding economie bijvoorbeeld kent vele richtingen die dusdanig van elkaar verschillen dat het weinig zin heeft om alle afgestudeerden van deze economie als één groep te beschouwen. Niet alleen verschillen de richtingen inhoudelijk sterk, afgestudeerden komen ook vaak in hele andere beroepen en sectoren op de arbeidsmarkt terecht. Daarnaast bestaan er opleidingen met eenzelfde naam maar met een andere CROHO-code. Dit komt voor wanneer de instroom van één van de opleidingen beëindigd is. Er kunnen in het kader van de WO-Monitor echter nog wel afgestudeerden van deze opleidingen benaderd worden. Tot slotte is gebleken dat enkele opleidingen in twee sectoren ingedeeld zijn, afhankelijk van de universiteit waar ze gegeven worden. Voor het coderen van vervolgopleidingen is gebruik gemaakt van de ROA-opleidingsclassificatie (8-digit).

Voor het coderen van beroepen is gebruik gemaakt van de Standaard Beroepen Classificatie (SBC) versie 1992 van het CBS. Deze classificatie is gebaseerd op een 5-digit code. Omdat er binnen enkele beroepen een verdere opsplitsing wenselijk was zijn er 6-digit codes toegevoegd. Zo is bijvoorbeeld het beroep 'Maatsch. werker reclas./kinderbesch./voogdij (hog.)' (oorspronkelijke SBC code op 5-digit niveau) verder onderverdeeld in 'Maatsch. werker reclassering (hog.)' en 'Maatsch. werker kinderbescherming/voogdij (hog.)' (toevoeging op 6-digit niveau). Bedrijven zijn gecodeerd aan de hand van de Standaard Bedrijfs Indeling (SBI) van het CBS (versie 1993). Ook hier zijn enkele codes op 6-digit niveau toegevoegd. $\mathrm{Er}$ is aan de lokale uitvoerders gevraagd om aan te geven of er nog nieuwe codes moesten worden toegevoegd op 6-digit niveau aan de SBI dan wel de SBC. Het zou mogelijk kunnen zijn dat men bepaalde beroepen niet op een voldoende gedetailleerd niveau kon coderen. Van deze mogelijkheid is nog geen gebruik gemaakt, maar verwacht wordt dat deze behoefte zal gaan ontstaan bij verder gebruik van de WO-Monitor. Voor het coderen van plaatsnamen is gebruik gemaakt van het PTT-postcode bestand. De volledige classificaties zijn te vinden in de documentatiemap van het landelijke onderzoeksbestand van de WOMonitor 1998. 


\section{Databeheer}

In het voorjaar 1999 is het 'Beheers- en gebruiksreglement WO-Monitor' geaccordeerd. In dit reglement is vastgelegd dat de VSNU de houder is van het bestand met als taak toezicht houden op de naleving van het reglement. Het meer technisch beheer van het bestand is ondergebracht bij het ROA. Als gebruikers en bewerkers van het bestand zijn aangemerkt de lokale uitvoerders. In het reglement is vastgelegd dat de beheerder en bewerkers erop toezien dat bij publicatie herkenning van individuele onderzoekseenheden niet mogelijk is. Als richtlijn is afgesproken dat elke groep waarover gerapporteerd wordt minimaal 5 waarnemingen bevat. Bovendien worden geen gegevens gepubliceerd die herleidbaar zijn tot afzonderlijke instellingen, tenzij na verkregen toestemming van de betreffende universiteit.

De gegevens van de WO-Monitor zijn in beginsel ook beschikbaar voor derden. In het reglement is aangegeven dat de gegevens van de WO-Monitor echter uitsluitend gebruikt mogen worden voor wetenschappelijk en statistisch onderzoek met als doel inzicht te bieden in de aansluiting tussen opleiding en werk en/of informatie te verschaffen aan afzonderlijke universiteiten in het kader van de kwaliteitszorg. Voor de levering aan derden geldt dat zij uitsluitend de beschikking krijgen over een geanonimiseerd bestand, zowel naar individu als naar instelling. Identificatie van afzonderlijke instellingen in het te leveren bestand aan derden is uitsluitend mogelijk na verkregen schriftelijke toestemming van de betrokken universiteiten.

Voor de gebruikers van het bestand is een documentatiemap beschikbaar waarin de vragenlijst is opgenomen en de constructie van nieuwe variabelen.

\section{Evaluatie}

In de voorafgaande hoofdstukken is op specifieke punten reeds een evaluatie gegeven van de uitvoering van de WO-Monitor 1998. Dit heeft ook reeds tot wijzigingen geleid in de vragenlijst en de planning voor de WO-Monitor 1999. In dit hoofdstuk zullen we de verschillende onderdelen puntsgewijs nalopen en aandachtspunten formuleren voor de uitvoering in 1999.

\section{Onderzoekspopulatie}

In het overleg met de begeleidingscommissie is vanuit de zijde van de VSNU gevraagd of het mogelijk is de onderzoekspopulatie uit te breiden met aio's, oio's en beurspromovendi. Geconstateerd is dat een dergelijke uitbreiding zinvol is, maar vooralsnog stuit op het ontbreken van een landelijk adressenbestand. Het is wenselijk dat de VSNU het initiatief neemt om tot een dergelijk landelijk bestand te komen.

Een tweede mogelijke uitbreiding heeft betrekking op afgestudeerden van tweede fase opleidingen met name de leraren- en ontwerpersopleidingen. Deze uitbreiding is makkelijker te realiseren en vindt op het gebied van de lerarenopleidingen ook reeds plaats. Het verdient 
aanbeveling om met ingang van 2000 de onderzoekspopulatie uit te breiden met deze tweede fase opleidingen.

Een derde uitbreiding heeft betrekking op het benaderen van cohorten die reeds langer geleden zijn afgestudeerd. In verschillende universiteiten is hiermee reeds ervaring opgedaan en een dergelijke uitbreiding van de monitor lijkt zeer wenselijk. Een longitudinale opzet verdient daarbij de voorkeur, waarbij een meetmoment na ruim één jaar en na ongeveer vijf jaar plaats vindt. Dat zou betekenen dat het cohort 1998 in 2002 opnieuw benaderd zou kunnen worden. Het verdient aanbeveling dat elke uitvoerder de betreffende onderzoek- en adresbestanden zodanig beheert dat een eventuele longitudinale meting mogelijk wordt. Definitieve besluitvorming in de VSNU zou plaats moeten vinden uiterlijk najaar 2001, zodat voldoende tijd resteert om de benodigde voorbereidingen te treffen. Bij de besluitvorming kunnen dan ook in voldoende mate de ervaringen met de eerdere monitoren betrokken worden.

\section{Vragenlijst}

Zoals aangegeven in hoofdstuk 3 hebben de ervaringen met de uitvoering van de Monitor in 1998 geleid tot een aantal aanpassingen. De belangrijkste conclusie is dat de vragenlijst letterlijk door de uitvoerders dient te worden overgenomen om te voorkomen dat ongewenste verschillen ontstaan.

\section{Dataverzameling}

De over-all respons op de WO-Monitor is met zo'n $50 \%$ als redelijk te classificeren. Vergeleken met ander schriftelijk onderzoek en gelet op de dalende responsbereidheid is er geen reden om tot algemene maatregelen over te gaan, zoals het drastisch inkorten van de huidige vragenlijst. Niettemin baren de verschillen in respons tussen de universiteiten wel zorgen. Onduidelijk is immers of deze verschillen in respons ook leiden tot een systematische vertekening. De eerste analyses op het materiaal (zie Kengetallenpublicatie) lijken overigens uit te wijzen dat van systematische verschillen in de arbeidsmarktpositie van afgestudeerden tussen universiteiten nauwelijks sprake is. Niettemin is het zinvol om de respons waar mogelijk te vergroten. Hierbij kunnen de volgende aandachtspunten worden geformuleerd:

- actualisering van adresbestanden;

- reminder en follow-up;

- begeleidende brief.

Het is zinvol de ervaringen op dit punt tussen de uitvoerders uit te wisselen.

Daarnaast zou onderzocht moeten worden in hoeverre systematische verschillen ontstaan door een afwijkende manier van bevraging, in casu de telefonische enquêtering door de Universiteit Utrecht.

\section{Coderen/classificatie}

Het zelf coderen van beroepen, bedrijven en opleidingen blijkt moeizaam te zijn. De meeste uitvoerders hebben afgelopen jaar gebruik gemaakt van de mogelijkheid om dit centraal te 
laten uitvoeren. Het verdient aanbeveling om komend jaar deze codering geheel centraal uit te voeren.

Daarnaast is het belangrijk dat de gebruikte classificaties verdere worden verfijnd om op die manier de gebruikswaarde voor het WO te optimaliseren. Hierbij kan met name gedacht worden aan het verder detailleren van de 'wetenschappelijke beroepen' in de Standaard Beroepen Classificatie van het CBS. Het ROA zal een coördinerende rol vervullen ten aanzien van voorstellen voor deze nadere detaillering. Het is zinvol om sectordeskundigen hierbij te betrekken. De VSNU kan dit inbrengen bij het discipline overleg. Specifieke aandacht behoeft de opleidingsclassificatie. Het blijkt dat de $\mathrm{CROHO}$ voor rapportage op het niveau van opleidingsrichtingen niet erg evenwichtig is samengesteld. Sommige opleidingen zijn te specifiek (en te klein) om afzonderlijk vermeld te worden, andere opleidingen blijken onderscheiden te worden, maar vertonen inhoudelijk een sterke overlap met andere opleidingen, terwijl weer andere opleidingen een diversiteit aan subrichtingen herbergen die juist wel onderscheiden moeten worden. Het is belangrijk dat een zinvolle indeling ontwikkeld wordt waarover gerapporteerd wordt. Dit valt buiten het kader van de WO-Monitor, omdat een dergelijke indeling ook buiten de WO-Monitor bruikbaar zou moeten zijn. De VSNU zou hierin het voortouw moeten nemen, waarbij het ROA een coördinerende rol kan vervullen ten aanzien van activiteiten in deze.

\section{Data-cleaning}

In het afgelopen uitvoeringsjaar heeft de data-cleaning volledig bij de lokale uitvoerders plaatsgevonden op basis van algemene richtlijnen. Gebleken is dat een dergelijke opzet in de praktijk niet goed werkt. Daarvoor zijn twee oorzaken aanwijsbaar. Om het goed te doen moet het protocol voor data-cleaning zo gedetailleerd zijn dat dit voor een lokale uitvoerder erg bewerkelijk wordt. Bovendien bleek de verslaglegging niet altijd adequaat, waardoor het achteraf zeer moeilijk bleek om te achterhalen welke regels men voor de cleaning gehanteerd heeft. We bevelen daarom aan om het protocol voor dataverwerking en -cleaning voor de lokale uitvoerders zo beperkt mogelijk te houden en te beperken tot richtlijnen voor de invoer van gegevens. De verdere data-cleaning (bijvoorbeeld het toekennen van missing values) kan dan centraal door het ROA uitgevoerd worden op basis van een voorstel dat met de technische werkgroep zal worden besproken. Het is belangrijk dat een dergelijk voorstel, tezamen met een voorstel voor de definitie van nieuwe centraal te hanteren variabelen reeds in december 1999 wordt vastgesteld.

\section{Databeheer}

In het afgelopen jaar is een discussie gevoerd over de vraag of instellingsspecifieke gegevens herkenbaar naar buiten mogen worden gebracht. Het verdient aanbeveling dat de SIB, op basis van de ervaringen met de monitor 1998, evalueert of de eis van anonimisering van instellingen gehandhaafd dient te worden. 
In de vergadering met de begeleidingscommissie in juni j.l. is naar voren gebracht dat de technische werkgroep een zwaardere rol krijgt bij de voorbereiding van de onderzoekswerkzaamheden. Om de tijdsbesteding van de leden van dit overleg zo efficiënt mogelijk te gebruiken, worden de voorstellen hieromtrent volledig door het ROA voorbereid. De rol van de begeleidingscommissie is vooral om de voortgang van het project als geheel te bewaken, en besluiten te nemen over strategische aanpassingen in het project.

\section{Planning}

Het afgelopen jaar is de oplevering van het landelijk bestand om verschillende redenen vertraagd. Een belangrijke oorzaak hiervoor was dat werkzaamheden aan het landelijk bestand pas kunnen plaats vinden wanneer alle lokale deelbestanden aanwezig zijn. Dit heeft geleid tot een aantal aanpassingen in de planning voor 1999. Het belangrijkste is dat het tijdstip voor oplevering van de deelbestanden vervroegd is naar 1 februari 2000 en de oplevering van het landelijk databestand op 1 maart 2000. 


\section{Bijlage 1: Vragenlijst WO-Monitor 1998}

\section{Vragenlijst WO-Monitor 1998}

versie 26 mei 1998

\section{A. PERSONALIA}

1. Wat is uw geboortejaar?

19

2. Sekse

1 man

2 vrouw

3. Postcode woonplaats (alleen de cijfers)

\section{B. OPLEIDING}

De volgende vragen hebben betrekking op de door $u$ afgeronde universitaire opleiding (eerste fase-opleiding of opleidingen tot basisarts, tandarts, dierenarts of apotheker). Indien $u$ verschillende universitaire opleidingen heeft gevolgd, wilt $u$ dan de vragen beantwoorden voor de opleiding die in de begeleidende brief wordt vermeld.

4. Aan welke universiteit haalde $u$ het einddiploma?

(bijlage; niet noodzakelijk als vraag: van tevoren bekend)

5. Welke opleiding betrof dit?

(CROHO-indeling/opleiding voordrukken)

6. Is dit een bovenbouwstudie zonder eigen propedeuse?
1 ja
ga naar vraag 7
2 nee
ga naar vraag 9

7. Op grond van welk voortraject bent u toegelaten tot de bij vraag 5 genoemde WO-opleiding?

1 WO-propedeuse, $\mathrm{nl}$........................................... ga naar vraag 8

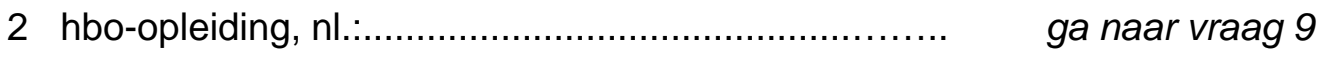

3 anders, $\mathrm{nl}$.:

8. Wanneer heeft u zich voor het eerst voor deze propedeuse-opleiding ingeschreven? maand:

ga naar vraag 11

jaar: 19

ga naar vraag 11 
9. Wanneer heeft $u$ zich voor het eerst voor de bij vraag 5 vermelde opleiding ingeschreven?

maand:

jaar: 19

10. Heeft u deze opleiding in voltijd of deeltijd gevolgd?

1 voltijd

2 deeltijd

3 combinatie van voltijd en deeltijd

11. Wanneer haalde $u$ het examen van deze opleiding?

maand:

jaar: 19

12. Heeft $u$ behalve de bij vraag 5 vermelde WO-opleiding nog een andere WO-opleiding afgerond?

1 nee

ga naar vraag 14

2 ja, namelijk:

$(\mathrm{CROHO})$

13. Wat is uw afstudeerdatum van deze WO-opleiding?

maand:

jaar: 19

14. Wat is uw hoogste in het voortgezet onderwijs behaalde diploma vóór de bij vraag 5 vermelde opleiding?

1 havo

$2 \mathrm{mbo}$

3 vwo

4 buitenlands diploma

5 anders

6 geen

15. Heeft u vóór en/of tijdens uw WO-opleiding voor uw vakgebied relevante werkervaring opgedaan? (Stages, afstudeeropdracht e.d. niet meerekenen).

1 nee

2 ja, in totaal maximaal één jaar

3 ja, in totaal langer dan een jaar

16. Bent u na uw WO-opleiding begonnen aan een andere opleiding (geen cursus)?

1 ja, nl. aio/oio

2 ja, nl. beurspromovendus

3 ja, nl. ontwerpersopleiding

4 ja, nl. lerarenopleiding

5 ja, andere post-doctorale beroepsvoorbereidende opleiding, $\mathrm{nl}$.:

$6 \mathrm{ja}$, een andere opleiding, nl.: 
17. Volgt u dit traject nog steeds?

1 ja

2 nee, voortijdig verlaten

3 nee, inmiddels voltooid

\section{WERKGELEGENHEIDSSITUATIE}

18. Welke van de onderstaande omschrijvingen zijn op uw huidige situatie van toepassing? (Meerdere antwoorden mogelijk).

1 betaald werk voor meer dan 12 uur per week

ga naar vraag 21

2 betaald werk voor minder dan 12 uur per week

ga naar vraag 20

3 studerend

4 onbetaald werk

5 werkloos

6 anders $\mathrm{nl}$.:

19. Heeft u na het verlaten van de opleiding betaald werk gehad?

1 ja

ga naar vraag 21

2 nee

20. Heeft u na het verlaten van de opleiding gezocht naar (ander) betaald werk?

1 ja

2 nee

einde vragenlijst

21. Heeft $u$ in de afgelopen vier weken iets gedaan om aan (ander) betaald werk te komen?

1 ja

2 nee, in afwachting van de uitkomst van een sollicitatie

3 nee

ga naar vraag 25

22. Stel, u vindt nú een (andere) baan. Hoe snel kunt u daarmee dan beginnen?

1 binnen 2 weken

ga naar vraag 24

2 tussen 2 weken en 3 maanden

3 na 3 maanden

23. Waarom kunt $u$ niet eerder beginnen?

1 opzeggen huidige baan

2 afronden vrijwilligerswerk

3 afronden opleiding/studie

4 regelen kinderopvang

5 vakantie

6 ziekte

7 andere reden, nl. 
24. Bent u ingeschreven bij het arbeidsbureau?

1 ja

2 nee

25. Hoeveel uren per week zou u betaald werk willen hebben?

(Rekening houdend met gevolgen voor inkomenssituatie).

( $V u l$ ' $O$ ' in als u geen betaald werk wilt hebben).

uren per week:

\section{ARBEIDSMARKTINTREDE/WERKERVARING}

26. Wanneer bent $u$ daadwerkelijk begonnen met het actief zoeken naar betaald werk? (S.v.p. één antwoord kiezen).

1 .......... maanden vóór afstuderen

2 meteen na afstuderen

3 ......... maanden na afstuderen

4 n.v.t. had huidige functie al tijdens opleiding ga naar vraag 32

27. Bij hoeveel werkgevers heeft $\mathrm{u}$, inclusief uw huidige werkgever, sinds uw afstuderen gewerkt? (Ook eigen bedrijf en uitzendperiodes apart meerekenen).

1 heb nog geen betaald werk gehad sinds afstuderen einde vragenlijst

2 ........... werkgevers

28. Hoeveel functies heeft u sinds uw afstuderen bij uw huidige werkgever bekleed?

(Inclusief uw huidige functie). functies

29. Hoeveel maanden heeft $u$ in totaal betaald werk verricht sinds uw afstuderen? maanden

30. Hoeveel maanden bent u na afstuderen onvrijwillig werkloos geweest vóór $u$ in uw eerste baan begon?

maanden

( Vul 'O' maanden in als u niet werkloos bent geweest).

31. Hoeveel maanden bent $u$ tot nu toe in totaal na uw afstuderen onvrijwillig werkloos geweest? maanden

( Vul 'O' maanden in als u niet werkloos bent geweest).

\section{E. KENMERKEN HUIDIGE FUNCTIE}

Indien $\mathrm{u}$ op dit moment geen betaald werk verricht zijn de volgende vragen niet van toepassing. U kunt volstaan met de reeds beantwoorde vragen. Indien u op dit moment méér dan één baan heeft, wilt u dan, tenzij anders aangegeven, bij de volgende vragen uitgaan van de 
functie met de meeste arbeidsuren. Een functie als aio/oio of beurspromovendus vatten we hier op als betaalde baan.

32. Wanneer bent u bij uw huidige werkgever begonnen?

maand:

jaar: 19

33. In welk dienstverband bent $\mathrm{u}$ in deze functie werkzaam?
1 werkzaam als aio/oio
ga naar vraag 35
2 werkzaam als beurspromovendus
ga naar vraag 35
3 uitzend-, oproep- of invalkracht
ga naar vraag 35
4 in loondienst bij werkgever (anders dan categorie 1 of 3)
ga naar vraag 34
5 freelance
ga naar vraag 35
6 zelfstandige in eigen bedrijf of praktijk
ga naar vraag 35
7 anders, $\mathrm{nl}$ :
ga naar vraag 35

34. Indien in loondienst, is uw arbeidsovereenkomst vast of tijdelijk?

1 (in proeftijd voor) vaste aanstelling/contract voor onbepaalde tijd

2 tijdelijke aanstelling van maanden met uitzicht op vaste aanstelling

3 tijdelijke aanstelling van maanden zonder uitzicht op vaste aanstelling

35. In wat voor organisatie of bedrijf werkt $u$ ?

(Bijvoorbeeld: academisch ziekenhuis, verpleeghuis, machinefabriek, bank, belastingkantoor, universiteit).

36. Wat voor soort product of dienst levert het bedrijf of de organisatie voornamelijk?

(Bijvoorbeeld: verpleging somatische patiënten, landbouwmachines, hypotheken, fiscaal advies, wetenschappelijk onderzoek).

37. (Optioneel: geef aan in welke bedrijfstak u werkzaam bent) (bijlage)

38. Wat is de postcode (alleen cijfergedeelte) van het bedrijf of de organisatie waar u werkt? (Het gaat hier om de vestiging waar u werkt. Indien buitenland s.v.p. het land invullen).

1 postcode:

2 buitenland, $\mathrm{nl}$ :

39. Welk opleidingsniveau werd (door uw werkgever) voor deze functie minimaal vereist?
1 WO-opleiding
2 hbo-opleiding
3 havo, vwo of mbo
4 mavo, vbo of lager 
40. Welke opleidings-/studierichting werd (door uw werkgever) voor deze functie vereist?

1 uitsluitend mijn eigen studierichting

2 mijn eigen of een verwante studierichting

3 een geheel andere dan mijn eigen studierichting

4 geen specifieke studierichting

41. Wat is de naam van uw huidige functie?

(Bijvoorbeeld: fiscaal adviseur, aio-openbare financiën, advocaat, gezondheidsvoorlichter, bedrijfsarts, AGNIO, beleidsmedewerker welzijn).

42. Wat zijn uw voornaamste werkzaamheden?

(Bijvoorbeeld: testresultaten analyseren, diagnoses stellen, lesgeven, marketingplan opstellen).

43. (Optioneel: geef uw huidige functie aan:)

(bijlage)

44. Aan hoeveel medewerkers geeft $u$ direct of indirect leiding?

1 geen

2 aan .......... personen

45. Hoeveel mensen werken er bij de organisatie of bedrijf waar u werkzaam bent? (Het gaat hier om alle werknemers van het totale concern; hoofd- en nevenvestigingen samen).

11 persoon

2 2-9 personen

3 10-99 personen

4100 of meer personen

46. Hoeveel uur per week werkt u formeel in deze functie?

(Indien in loondienst: de omvang van uw arbeidscontract, bij wisselende werkweken: een gemiddelde werkweek).

..........uur

47. Wat is uw bruto maandinkomen in uw huidige (hoofd)functie?

- incl. provisie, toeslag ploegen/onregelmatige tijden

- excl. overwerk, 13e maand, winstdeling, gratificaties, kinderbijslag, vakantiegeld, vergoeding reiskosten e.d.

- excl. eventuele uitkering (RWW, WW, WAO e.d.)

- excl. inkomsten uit nevenfuncties

- ga bij wisselende verdiensten uit van gemiddelde

fl. 
48. Heeft $u$ op dit moment nog één of meer betaalde nevenfuncties naast de bij de voorafgaande vragen beschreven baan?

1 ja

2 nee

laatste vraag

49. Hoeveel uur per week werkt u over alle nevenfuncties gerekend?

(Indien in loondienst: de omvang van uw arbeidscontract, bij wisselende werkweken: een gemiddelde werkweek).

- excl. hoofdfunctie 


\section{Bijlage 2: Vragenlijst WO-Monitor 1999}

\section{Vragenlijst WO-Monitor 1999}

versie 6 juli 1999

\section{A. PERSONALIA}

1. Wat is uw geboortejaar?

2. Sekse

1 man

2 vrouw

3. Postcode woonplaats

- alleen de cijfers

- indien buitenland s.v.p. het land invullen

1 postcode

2 buitenland, nl:

\section{B. OPLEIDING}

De volgende vragen hebben betrekking op de door $u$ afgeronde universitaire opleiding (eerste fase opleiding of opleidingen tot basisarts, tandarts, dierenarts of apotheker). Indien u verschillende universitaire opleidingen heeft gevolgd, wilt $u$ dan vragen beantwoorden voor de opleiding die in de begeleidende brief wordt vermeld.

4. Aan welke universiteit haalde $u$ het einddiploma?

(bijlage; niet noodzakelijk als vraag: van tevoren bekend)

5. Welke opleiding betrof dit?

(opleiding voordrukken)

6. Stond u (overwegend) voor de voltijd- of de deeltijd-variant van deze opleiding ingeschreven?

1 voltijd

2 deeltijd

7. Wanneer haalde $u$ het examen van deze opleiding?

maand:

jaar:.

8. Hoe bent $\mathrm{u}$ aan deze WO-opleiding begonnen?

1 direct ingestroomd in de propedeuse behorend bij de eigen opleiding

2 indirect ingestroomd via de propedeuse van een andere WO-opleiding, nl.:

3 ná de propedeuse ingestroomd op basis van een hbo-opleiding, $\mathrm{nl}$.: 
4 ná de propedeuse ingestroomd op basis van een ander voortraject, nl.:

9. Wanneer heeft $\mathrm{u}$ zich voor het eerst voor deze WO-opleiding ingeschreven? (Let op: inclusief de eventuele in vraag 8 genoemde (eigen of andere) WOpropedeuse).

maand

jaar:

10. Heeft u vóór of tijdens deze WO-opleiding nog een andere WO-opleiding afgerond?

1 nee

2 ja, namelijk: $(\mathrm{CROHO})$

$\rightarrow \quad$ ga naar vraag 12

11. Wat is uw afstudeerdatum van deze andere WO-opleiding?

maand:

jaar:.

12. Wat is uw hoogste met diploma afgesloten opleiding vóór uw eerste inschrijving in het WO?

1 vwo, hbs of gymnasium

2 hbo

3 buitenlands diploma

4 anders, $\mathrm{nl}$.:

5 geen

13. Heeft u vóór en/of tijdens uw WO-opleiding voor uw vakgebied relevante werkervaring opgedaan?

- zowel betaald als onbetaald werk telt mee

- stages, afstudeeropdracht e.d. niet meerekenen

1 nee

2 ja, in totaal maximaal één jaar

$3 \mathrm{ja}$, in totaal langer dan één jaar

14. Heeft u tijdens uw WO-opleiding ervaring in het buitenland opgedaan?

(Let op: meerdere antwoorden mogelijk)

$1 \mathrm{ja}$, onderzoeksstage gelopen in het buitenland

2 ja, praktijkstage gelopen in het buitenland

3 ja, studie-onderdeel gevolgd in het buitenland

4 ja, andere buitenlandervaring

5 nee

15. Heeft u na uw WO-opleiding een andere opleiding gevolgd of voortgezet?

(Geen cursus).

1 ja, nl. aio/oio

2 ja, nl. beurspromovendus

3 ja, nl. ontwerpersopleiding 
4 ja, nl. lerarenopleiding

5 ja, andere post-doctorale beroepsvoorbereidende opleiding, $\mathrm{nl}$.

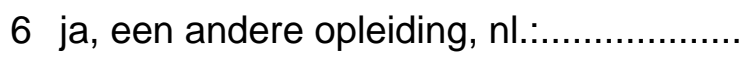

7 nee

16. Volgt/volgde $u$ deze vervolgopleiding opleiding (overwegend) in voltijd of deeltijd?

1 voltijd

2 deeltijd

17. Volgt u dit traject nog steeds?

1 ja

2 nee, voortijdig verlaten

3 nee, inmiddels voltooid

\section{WERKGELEGENHEIDSSITUATIE}

18. Welke van de onderstaande omschrijvingen zijn op uw huidige situatie van toepassing? (Meerdere antwoorden mogelijk).

1 betaald werk voor 12 uur of meer per week

2 betaald werk voor minder dan 12 uur per week

3 studerend

4 onbetaald werk

5 werkloos

6 anders, nl.:

19. Welke van de in vraag 18 genoemde omschrijvingen is het meest op uw huidige situatie van toepassing? (Geef het betreffende nummer).

20. Heeft $u$ in de afgelopen vier weken iets gedaan om aan (ander) betaald werk te komen? (Advertenties nakijken om een baan te vinden telt al mee).

1 ja

2 nee, in afwachting van de uitkomst van een sollicitatie

3 nee

21. Hoeveel uren per week zou u het liefst betaald werk willen hebben? (Rekening houdend met gevolgen voor inkomenssituatie).

1 ik wil geen betaald werk hebben $\quad \rightarrow \quad$ ga naar vraag 24

2 ik wil betaald werk voor ........ uren per week

22. Stel, u vindt nú een (andere) baan. Hoe snel kunt u daarmee beginnen?
1 binnen 2 weken
2 tussen 2 weken en 3 maanden
ga naar vraag 24
3 na 3 maanden 
23. Waarom kunt u niet eerder beginnen?

1 opzeggen huidige baan

2 afronden vrijwilligerswerk

3 afronden opleiding/studie

4 regelen kinderopvang

5 vakantie

6 ziekte

7 andere reden, $\mathrm{nl}$.

24. Bent $u$ ingeschreven bij het arbeidsbureau?

1 ja

2 nee

\section{ARBEIDSMARKTINTREDE/WERKERVARING}

25. Heeft u tijdens of ná de opleiding gezocht naar betaald werk?

- niet het zoeken naar bijbaantjes of vakantiebanen

- een functie als aio/oio of beurspromovendus vatten we hier op als een betaalde baan

1 ja

2 nee

$\rightarrow \quad$ ga naar vraag 27

26. Wanneer bent $u$ daadwerkelijk begonnen met actief zoeken naar betaald werk? (S.v.p. één antwoord kiezen).

1 ........ maanden vóór afronding laatste studieonderdeel

2 meteen na afronding laatste studieonderdeel

3 ......... maanden ná afronding laatste studieonderdeel

27. Hoeveel maanden bent u na uw afstuderen onvrijwillig werkloos geweest vóór u in uw eerste baan begon?

( Vul ' $O$ ' in als u niet werkloos bent geweest). maanden

28. Hoeveel maanden bent $\mathrm{u}$ in totaal na uw afstuderen onvrijwillig werkloos geweest?

( Vul 'O' in als u niet werkloos bent geweest). maanden

29. Bij hoeveel werkgevers, inclusief uw huidige werkgever, heeft u sinds uw afstuderen gewerkt?

- tel uitzendperiodes ieder afzonderlijk mee

- tel eigen bedrijf en eventuele nevenfuncties ook mee

$1 \mathrm{ik}$ heb geen betaald werk gehad sinds afstuderen $\rightarrow$ einde vragenlijst

2 ...... werkgevers 
30. Hoeveel functies heeft u sinds uw afstuderen bij uw huidige werkgever bekleed? (Inclusief uw huidige functie). functies

31. Hoeveel maanden heeft $u$ in totaal betaald werk verricht sinds uw afstuderen? maanden

\section{E. KENMERKEN HUIDIGE FUNCTIE}

32. Heeft u op dit moment betaald werk?

- een functie als aio/oio of beurspromovendus vatten we ook hier op als een betaalde baan

1 ja

2 nee $\rightarrow$ einde vragenlijst

Indien $u$ op dit moment méér dan één baan heeft, wilt $u$ dan, tenzij anders aangegeven, bij de volgende vragen uitgaan van de functie met de meeste arbeidsuren.

33. Wanneer bent u bij uw huidige werkgever begonnen?

...... maand jaar

34. In welk dienstverband bent $\mathrm{u}$ in deze functie werkzaam?

1 werkzaam als aio/oio

2 werkzaam als beurspromovendus

3 uitzend-, oproep- of invalkracht

4 in loondienst bij werkgever (anders dan categorie 1 of 3 )

5 freelance

6 zelfstandige in eigen bedrijf

7 anders, nl.:

35. Is uw arbeidsovereenkomst vast of tijdelijk?

1 (in proeftijd voor) vaste aanstelling/contract voor onbepaalde tijd

2 tijdelijke aanstelling van .... maanden met uitzicht op vaste aanstelling

3 tijdelijke aanstelling van .... maanden zonder uitzicht op vaste aanstelling

4 n.v.t., niet in loondienst

36. In wat voor organisatie of bedrijf werkt u? (Bijvoorbeeld: academisch ziekenhuis, verpleeghuis, machinefabriek, bank, belastingkantoor, universiteit).

37. Wat voor soort product of dienst levert het bedrijf of de organisatie voornamelijk? (Bijvoorbeeld: verpleging somatische patiënten, landbouwmachines, hypotheken, fiscaal advies, wetenschappelijk onderzoek) 
38. Wat is de postcode (alleen cijfergedeelte) van het bedrijf of de organisatie waar $u$ werkt? (Het gaat hier om de vestiging waar u werkt. Indien buitenland s.v.p. het land invullen).

1 postcode ........

2 buitenland, $\mathrm{nl}$.:

39. Welk opleidingsniveau werd (door uw werkgever) voor deze functie minimaal vereist?
1 WO-opleiding
$\rightarrow \quad$ ga naar vraag 41
2 hbo-opleiding
3 havo, vwo of mbo
4 mavo, vbo of lager
$\rightarrow \quad$ ga naar vraag 41
$\rightarrow \quad$ ga naar vraag 41

40. Werd door uw werkgever specifiek om een hbo-er met een bepaalde opleidingsrichting gevraagd, werd in algemene zin om iemand met een hbo-werk- en denkniveau gevraagd of - nog iets ruimer - werd om een hbo- of academisch niveau gevraagd?

1 werd specifiek een hbo-er gevraagd?

2 werd hbo- werk- en/of denkniveau gevraagd?

3 werd hbo- of academisch werk- en/of denkniveau gevraagd?

41. Welk opleidingsniveau past (volgens uzelf) het beste bij uw huidige werkzaamheden?
1 WO-opleiding
2 hbo-opleiding
3 havo, vwo of mbo
4 mavo, vbo of lager

42. Welke opleidings-/studierichting werd (door uw werkgever) voor uw functie vereist?

1 uitsluitend mijn eigen studierichting

2 mijn eigen of een verwante studierichting

3 een geheel andere dan mijn eigen studierichting

4 geen specifieke studierichting

43. Wat is de naam van uw huidige functie?

(Bijvoorbeeld: fiscaal adviseur, aio-openbare financiën, advocaat, gezondheids- voorlichter, bedrijfsarts, AGNIO, beleidsmedewerker welzijn).

44. Wat zijn uw voornaamste werkzaamheden?

(Bijvoorbeeld: testresultaten analyseren, diagnoses stellen, lesgeven, marketingplan opstellen).

45. Aan hoeveel medewerkers geeft u direct of indirect leiding?

1 geen

2 aan ....... personen

46. Hoeveel mensen werken er bij de organisatie of het bedrijf waar u werkzaam bent? 
(Het gaat hier om alle werknemers van het totale concern; hoofd- en nevenvestigingen samen).

11 persoon

2 2-9 personen

3 10-99 personen

4100 of meer personen

47. Uit hoeveel uren per week bestaat een voltijdbetrekking bij uw bedrijf of organisatie? (Indien $u$ als zelfstandige/in freelance werkt: uren feitelijk gewerkt in een gemiddelde werkweek).

..... uur per week

48. Heeft $\mathrm{u}$ in uw huidige functie een voltijdbetrekking?

(Indien in loondienst: ga uit van de omvang van uw arbeidscontract; bij wisselende werkweken: een gemiddelde werkweek).

1 ja

2 nee, ik heb een aanstelling voor ....... \%

49. Wat is uw bruto maandinkomen in uw huidige (hoofd)functie?

incl. provisie, toeslag ploegen/onregelmatige tijden; excl. overwerk, 13e maand, winstdeling, gratificaties, kinderbijslag, vakantiegeld, vergoeding reiskosten, e.d.; excl. eventuele uitkering (RWW, WW, WAO e.d.); excl. inkomsten uit nevenfuncties.

(Ga bij wisselende verdiensten uit van gemiddelde).

fl. per maand

50. Heeft u op dit moment nog één of meer betaalde nevenfuncties naast de bij de voorafgaande vragen beschreven baan?
1 ja
2 nee

$\rightarrow \quad$ einde vragenlijst

51. Hoeveel uur per week werkt u over alle nevenfuncties gerekend?

(Indien in loondienst: de omvang van uw arbeidscontract, bij wisselende werkweken: een gemiddelde werkweek).

- excl. hoofdfunctie

..... uur per week

52. Hoeveel verdient $u$ in totaal bruto per maand in deze nevenfuncties?

incl. provisie, toeslag ploegen/onregelmatige tijden; excl. overwerk, $13 \mathrm{e}$ maand, winstdeling, gratificaties, kinderbijslag, vakantiegeld, vergoeding reiskosten, e.d.; excl. eventuele uitkering (RWW, WW, WAO e.d.).

( $G$ a bij wisselende verdiensten uit van gemiddelde).

fl. per maand 